TITLE:

\title{
Crystal structure and thermoelectric properties of type-I clathrate compounds in the Ba-Ga- Ge system
}

\section{$\operatorname{AUTHOR}(\mathrm{S}):$}

Okamoto, NL; Kishida, K; Tanaka, K; Inui, H

\section{CITATION:}

Okamoto, NL ... [et al]. Crystal structure and thermoelectric properties of type-I clathrate compounds in the Ba-Ga-Ge system. JOURNAL OF APPLIED PHYSICS 2006, 100(7): 073504.

\section{ISSUE DATE:}

2006-10-01

URL:

http://hdl.handle.net/2433/50068

\section{RIGHT:}

Copyright 2006 American Institute of Physics. This article may be downloaded for personal use only. Any other use requires prior permission of the author and the American Institute of Physics. 


\title{
Crystal structure and thermoelectric properties of type-I clathrate compounds in the Ba-Ga-Ge system
}

\author{
Norihiko L. Okamoto, a) Kyosuke Kishida, Katsushi Tanaka, and Haruyuki Inui \\ Department of Materials Science and Engineering, Kyoto University, Sakyo-ku, Kyoto 606-8501, Japan
}

(Received 16 February 2006; accepted 23 July 2006; published online 3 October 2006)

\begin{abstract}
The crystal structure and thermoelectric properties of type-I clathrate compounds in the $\mathrm{Ba}-\mathrm{Ga}-\mathrm{Ge}$ system have been investigated as a function of Ga content. The solid solubility of Ga in the type-I clathrate compounds is determined to be $X=16$ when expressed with the formula of $\mathrm{Ba}_{8} \mathrm{Ga}_{X} \mathrm{Ge}_{46-X}$. As the Ga content increases, the crystal structure changes from a superlattice structure to the normal type-I clathrate structure with the transition occurring at $X=3.5-5$. The density of Ge vacancies in the type-I clathrate phase decreases as the Ga content increases. The absolute values of electrical resistivity and Seebeck coefficient increase, while that of lattice thermal conductivity decreases with the increase in the Ga content. The changes in electrical resistivity and Seebeck coefficient are explained in terms of the number of excess electrons, while the change in lattice thermal conductivity is explained in terms of the extent of the rattling motion of $\mathrm{Ba}$ atoms encapsulated in the cage structure. (C) 2006 American Institute of Physics. [DOI: 10.1063/1.2355443]
\end{abstract}

\section{INTRODUCTION}

Clathrate compounds exhibit relatively low electrical resistivity and high Seebeck coefficient in addition to very low thermal conductivity. ${ }^{1-3}$ Clathrate compounds have been investigated in recent years as promising thermoelectric materials, since the thermoelectric performance is evaluated with the dimensionless figure of merit ZT $=\alpha^{2} T /(\rho \lambda)$, where $\alpha, \rho$, $\lambda$, and $T$ stand for Seebeck coefficient, electrical resistivity, thermal conductivity, and temperature, respectively. The crystal structure of clathrate compounds is comprised of polyhedral cages and guest atoms encapsulated in the cages. The cages consist of group IV and/or III elements (Tt), while the guest atoms $(M)$ are typically alkali metals or alkalineearth metals. Clathrate compounds, to which intensive investigation as possible thermoelectric materials is recently made, are those categorized as "type I" with the chemical formula of $M_{8} \mathrm{Tt}_{46}$, in which the cubic unit cell consists of two pentagonal dodecahedra $\left(\mathrm{Tt}_{20}\right.$ cage) and six tetrakaidecahedra $\left(\mathrm{Tt}_{24}\right.$ cage) encapsulating guest atoms $(M) .{ }^{4}$ The space group of type-I clathrate compounds is $P m \overline{3} n$ and Tt atoms constituting the cage structure are located in $6 c, 16 i$, and $24 k$ sites, whereas guest atoms are in $2 a$ and $6 d$ sites. Tt atoms are tetrahedrally bonded to each other, while guest atoms are weakly bonded to the cage structure. Low thermal conductivity of type-I clathrate compounds is considered to originate from the rattling motion of guest atoms in $6 d$ sites, which is detected by $\mathrm{x}$-ray and neutron diffractions as an anomalously large atomic displacement parameter (ADP). ${ }^{5}$

Some binary type-I clathrate compounds such as $\mathrm{Ba}_{8} \mathrm{Ge}_{43},{ }^{6-9} \mathrm{Rb}_{8} \mathrm{Sn}_{44},{ }^{10} \mathrm{~K}_{8} \mathrm{Ge}_{44},{ }^{11}$ and $\mathrm{Cs}_{8} \mathrm{Sn}_{44},{ }^{12}$ have been reported to contain vacancies in the cage structure. While vacancies in $\mathrm{Rb}_{8} \mathrm{Sn}_{44},{ }^{10} \mathrm{~K}_{8} \mathrm{Ge}_{44},{ }^{11}$ and $\mathrm{Cs}_{8} \mathrm{Sn}_{44}$ (Ref. 12) are reported to randomly occupy $6 c$ sites, our recent study by

\footnotetext{
${ }^{a)}$ Author to whom correspondence should be addressed; electronic mail: nlokamoto@ucdavis.edu
}

electron diffraction and synchrotron powder diffraction ${ }^{8,9}$ has indicated that $\mathrm{Ba}_{8} \mathrm{Ge}_{43}$ possesses a superlattice structure of cubic symmetry with a lattice parameter twice that of the normal type-I clathrate structure due to an ordered arrangement of Ge vacancies and that the space group is $I a \overline{3} d$ with Ge atoms and vacancies exclusively in $24 d$ and $24 c$ sites, respectively. The $24 c$ and $24 d$ sites in the superlattice structure correspond to $6 c$ sites in the normal type-I clathrate structure, based on which the superlattice structure is formed. The binary type-I clathrate compound $\mathrm{Ba}_{8} \mathrm{Ge}_{43}$ is unstable and decomposes into the type-III clathrate $\left(\mathrm{Ba}_{24} \mathrm{Ge}_{100}\right)$ and Ge phases below $770{ }^{\circ} \mathrm{C}^{7}$ The thermoelectric properties of $\mathrm{Ba}_{8} \mathrm{Ge}_{43}$ are not particularly good, as exemplified by a rather low ZT value of 0.057 . However, once alloyed with a large amount of $\mathrm{Ga}$, the crystal structure is reported to be of the normal type-I clathrate, for example, for $\mathrm{Ba}_{8} \mathrm{Ga}_{16} \mathrm{Ge}_{30}$, indicating the existence of phase transformation from the superlattice structure for $\mathrm{Ba}_{8} \mathrm{Ge}_{43}$ to the normal type-I structure for $\mathrm{Ba}_{8} \mathrm{Ga}_{16} \mathrm{Ge}_{30}$ at some composition in between. The thermoelectric property is reported to be improved accordingly once the crystal structure is changed to that of the normal type I so that the ZT value of 1.0 is achieved at high temperatures for $\mathrm{Ba}_{8} \mathrm{Ga}_{16} \mathrm{Ge}_{30} \cdot{ }^{13,14}$ In some type-I clathrate compounds, some ternary elements ${ }^{15,16}$ as well as vacancies ${ }^{10-12}$ are reported to preferentially occupy $6 c$ sites, as Ge vacancies in $\mathrm{Ba}_{8} \mathrm{Ge}_{43}$ preferentially occupy the corresponding sites ( $24 c$ sites) in the superlattice structure. Since the $6 c$ sites of the normal type-I clathrate compounds correspond to the linkage points of four tetrakaidecahedral cages, the occupancy behavior in $6 c$ sites may play an important role in determining the transport properties. Upon phase transformation from the superlattice structure for $\mathrm{Ba}_{8} \mathrm{Ge}_{43}$ to the normal type-I structure for $\mathrm{Ba}_{8} \mathrm{Ga}_{16} \mathrm{Ge}_{30}$, not only the concentration of vacancies in $6 c$ sites but also the occupancy behavior in the sites may vary with the Ga content.

In the present study, we investigate phase equilibria among phases existing near the type-I clathrate phase in the 
$\mathrm{Ba}-\mathrm{Ga}-\mathrm{Ge}$ system and crystal structures of $\mathrm{Ba}-\mathrm{Ga}-\mathrm{Ge}$ ternary type-I clathrate compounds in order to determine the solubility limit of $\mathrm{Ga}$ in the type-I clathrate phase and the occupancy behavior of $\mathrm{Ge} / \mathrm{Ga}$ atoms and vacancies in the $6 c$ sites, respectively. We also investigate the thermoelectric properties of $\mathrm{Ba}-\mathrm{Ga}-\mathrm{Ge}$ ternary type-I clathrate compounds as functions of $\mathrm{Ga}$ content and temperature. Implication is made on the correlation between the deduced crystallographic features and the observed thermoelectric properties.

\section{EXPERIMENTAL PROCEDURES}

Specimens with nominal compositions of $\mathrm{Ba}_{8} \mathrm{Ga}_{X} \mathrm{Ge}_{46-X}$ $(X=3,4.5,6,12,16$, and 18) were prepared by Ar arc melting. After arc melting, specimens were annealed at $790{ }^{\circ} \mathrm{C}$ in vacuum for $12 \mathrm{~h}$ followed either by oil quenching or by furnace cooling. Microstructures and chemical compositions of phases present in oil-quenched and furnace-cooled specimens were examined by scanning electron microscopy (SEM) and energy dispersive x-ray spectroscopy (EDS), respectively. Annealed samples were ground to powder with a particle size less than $16 \mu \mathrm{m}$ and were encapsulated into quartz capillary with a diameter of $300 \mu \mathrm{m}$. Synchrotron powder diffraction experiments were carried out at room temperature with a Debye-Scherrer camera and an imaging plate detector installed at the BL02B2 beamline of the SPring- 8 . The wavelength of the incident $\mathrm{x}$ ray used was $0.05000 \mathrm{~nm}$. Crystal structure refinement was made by the Rietveld method with the RIETAN-2000 program. ${ }^{17}$ Measurements of electrical resistivity and Seebeck coefficient were made with our ULVAC ZEM-2 apparatus in the temperature range from 50 to $670{ }^{\circ} \mathrm{C}$. Measurements of thermal conductivity $\left(\lambda_{\mathrm{RT}}\right)$ were carried out at room temperature (RT) by the static method. Values of thermal conductivity above room temperature $\left(\lambda_{T}\right)$ were calculated from the values of thermal diffusivity $\left(\kappa_{T}\right.$ and $\kappa_{\mathrm{RT}}$; those at a given temperature and room temperature, respectively) determined by the laser flash method with the following equation:

$$
\lambda_{T}=\lambda_{\mathrm{RT}} \times \kappa_{T} / \kappa_{\mathrm{RT}},
$$

on the basis that the values of specific heat for type-I clathrate compounds $\mathrm{Ba}_{8} \mathrm{Ga}_{X} \mathrm{Ge}_{46-X}$ are constant above room temperature. $^{18}$

\section{RESULTS}

\section{A. Phase identification}

While microstructures after oil quenching and furnace cooling are identical to each other for specimens with $X$ $\geqslant 6$, those for specimens with $X=3$ and 4.5 are different from each other. SEM backscattered electron images of specimens with $X=3$ and 4.5 after oil quenching and furnace cooling are illustrated in Figs. 1(a) and 1(b) and Figs. 1(c) and 1(d), respectively. After oil quenching, a two-phase microstructure consisting of type-I clathrate and Ge phases is similarly observed for both specimens [Figs. 1(a) and 1(c)]. The volume fraction of the Ge phase is generally larger for the specimen with $X=3$ than that with $X=4.5$, implying that the density of $\mathrm{Ge}$ vacancies in the type-I clathrate compounds decreases with the increase in the Ga content. After
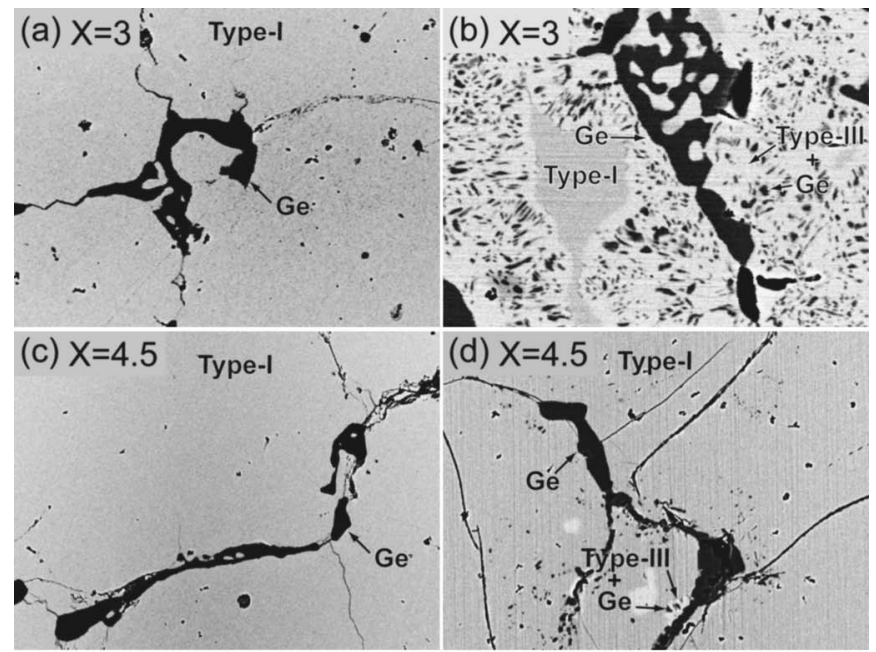

(d) $X=4.5$ : Type-1
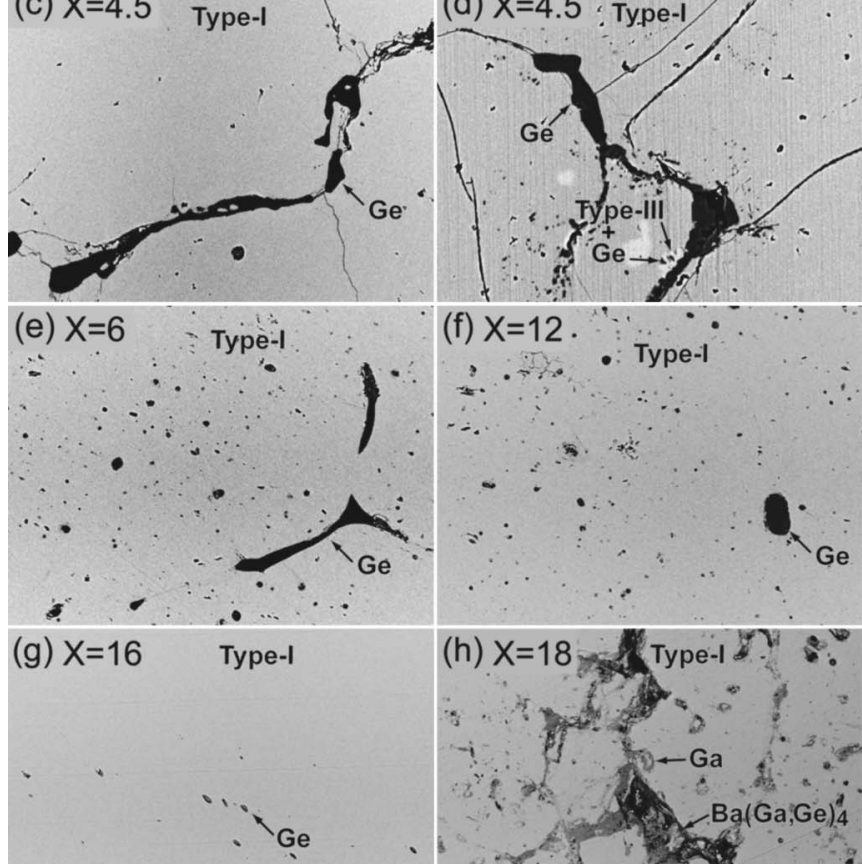

$50 \mathrm{~mm}$

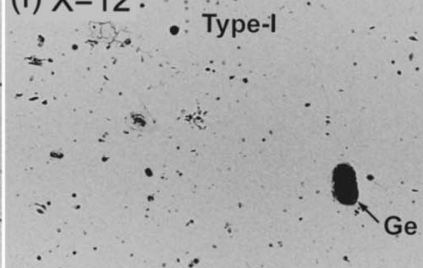

Ge

FIG. 1. SEM backscattered electron images of oil-quenched specimens with (a) $X=3$ and (c) $X=4.5$ and furnace-cooled specimens with (b) $X=3$, (d) $X=4.5$, (e) $X=6$, (f) $X=12$, (g) $X=16$, and (h) $X=18$.

furnace cooling, the specimen with $X=3$ exhibits a fine microstructure consisting of type-III $\left(\mathrm{Ba}_{24} \mathrm{Ga}_{9.5} \mathrm{Ge}_{90.5}\right)$ and $\mathrm{Ge}$ phases in addition to type-I clathrate and Ge phases [Fig. 1(b)]. A similar microstructure is observed for the specimen with $X=4.5$ after furnace cooling although the volume fraction of the fine microstructure consisting of type-III and Ge phases is considerably decreased. The formation of the fine microstructure consisting of type-III and Ge phases is believed to be due to the decomposition of the type-I clathrate phase into type-III and Ge phases during cooling, as is observed in the binary type-I clathrate compound $\mathrm{Ba}_{8} \mathrm{Ge}_{43}{ }^{7}{ }^{7}$ This implies that the type-I clathrate compounds in specimens with $X=3$ and 4.5 have a superlattice structure with an ordered arrangement of Ge vacancies and are unstable at low temperatures, as in the case of the binary type-I clathrate compound $\mathrm{Ba}_{8} \mathrm{Ge}_{43}{ }^{7}$ On the other hand, only type-I clathrate and Ge phases are observed for specimens with $X=6,12$, and 16 [Figs. 1(e) $-1(\mathrm{~g})$ ] both after oil quenching and furnace cooling, indicating that the thermal stability of the type-I clathrate compounds in these specimens is increased so that the decomposition into type-III and Ge phases no longer occurs during cooling. Of interest to note is that the volume fraction of the Ge phases decreases with the increase in the 
TABLE I. Ga and Ge contents in the type-I clathrate compounds obtained by EDS analyses. In the analyses, the $\mathrm{Ba}$ sites are assumed to be fully occupied.

\begin{tabular}{lclc}
\hline \hline $\begin{array}{c}\text { Nominal } \\
\text { composition }\end{array}$ & Ga content & Ge content & Ga+Ge \\
\hline $\mathrm{Ba}_{8} \mathrm{Ga}_{3} \mathrm{Ge}_{43}$ & $3.93(11)$ & $38.96(12)$ & $42.35(16)$ \\
$\mathrm{Ba}_{8} \mathrm{Ga}_{4.5} \mathrm{Ge}_{41.5}$ & $4.72(7)$ & $36.99(8)$ & $42.71(10)$ \\
$\mathrm{Ba}_{8} \mathrm{Ga}_{6} \mathrm{Ge}_{40}$ & $6.66(7)$ & $37.14(9)$ & $43.80(11)$ \\
$\mathrm{Ba}_{8} \mathrm{Ga}_{12} \mathrm{Ge}_{34}$ & $13.34(8)$ & $30.77(8)$ & $44.11(11)$ \\
$\mathrm{Ba}_{8} \mathrm{Ga}_{16} \mathrm{Ge}_{30}$ & $16.30(13)$ & $28.25(11)$ & $44.55(17)$ \\
$\mathrm{Ba}_{8} \mathrm{Ga}_{18} \mathrm{Ge}_{28}$ & $16.47(18)$ & $28.20(21)$ & $44.67(27)$ \\
\hline \hline
\end{tabular}

Ga content for specimens with $X=6,12$, and 16. For the specimen with $X=18$, a three-phase microstructure consisting of type-I clathrate, $\mathrm{Ba}(\mathrm{Ga}, \mathrm{Ge})_{4}$, and $\mathrm{Ga}$ phases is identified [Fig. 1(h)]. EDS analysis (Table I) has indicated that the chemical composition of the type-I phase in the specimen with $X=18$ is almost identical to that in the specimen with $X=16$. This clearly indicates that the solid solubility of $\mathrm{Ga}$ in the Ba-Ge type-I clathrate phase is close to $X=16$ but never exceeds $X=18$.

The oil-quenched specimen with $X=3$ and furnacecooled specimens with $X=4.5-16$ were analyzed by $\mathrm{x}$-ray powder diffraction with synchrotron radiation. Figure 2(a) shows the observed diffraction patterns in the $2 \theta$ range from $3.5^{\circ}$ to $9^{\circ}$ for binary ${ }^{9}$ and Ga-containing ternary specimens. Broad backgrounds are due to the quartz capillary. Some superlattice reflections are observed in the pattern of the specimen with $X=3$, as indicated with solid arrows in Fig. 2(a), and the positions of these superlattice reflections are the same as those of $\mathrm{Ba}_{8} \mathrm{Ge}_{43} .{ }^{9}$ On the other hand, no superlattice reflections are observed in the patterns of specimens with $X=4.5-16$. These $\mathrm{x}$-ray diffraction patterns indicate that the type-I clathrate phase in the oil-quenched specimen with $X$ $=3$ possesses a superlattice structure which is the same as that (space group $I a \overline{3} d$ ) of the binary type-I clathrate compound $\mathrm{Ba}_{8} \mathrm{Ge}_{43}$, while that in the furnace-cooled specimens with $X=4.5-16$ possesses the normal type-I clathrate structure (space group $\operatorname{Pm} \overline{3} n$ ). For all the specimens, reflections from the Ge phase are observed in the diffraction patterns as indicated by open arrows in Fig. 2. When judged from the relative intensity, the volume fraction of the Ge phase in specimens with $X=3-16$ seems to decrease with the increase in the Ga content, being consistent with the SEM observations (Fig. 1). Some reflections corresponding to the type-III clathrate phase are observed in the pattern of the specimen with $X=4.5$, as indicated by double arrows in Fig. 2(a). The type-III clathrate phase observed in the specimen with $X$ $=4.5$ is considered to be the product phase of the decomposition reaction of the superlattice type-I clathrate phase that coexists with the Ge and normal type-I clathrate phases at $790{ }^{\circ} \mathrm{C}$ [see the phase diagram of Fig. 3(a)].

Table I shows the Ga and Ge contents in the type-I clathrate compounds obtained by EDS analyses. In the analyses, the $\mathrm{Ba}$ sites are assumed to be fully occupied (i.e., the $\mathrm{Ba}$ content is fixed to be 8 per unit formula). Since the threephase microstructure consisting of type-I clathrate,
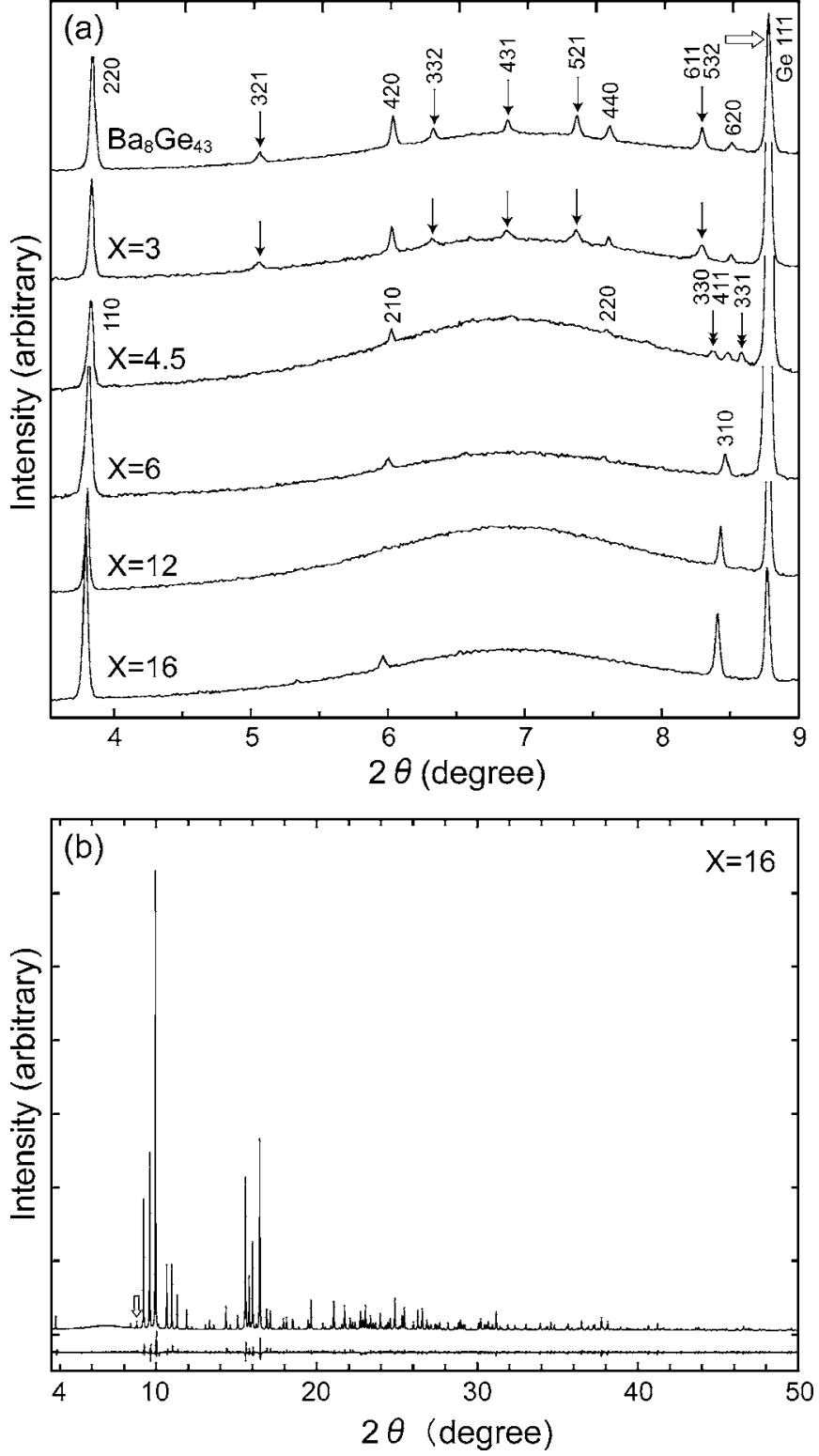

FIG. 2. (a) X-ray powder diffraction patterns in the $2 \theta$ range from $3.5^{\circ}$ to $9^{\circ}$ for the oil-quenched specimen with $X=3$ and furnace-cooled specimens with $X=4.5,6,12$, and 16 . The pattern for the binary type-I clathrate compound $\mathrm{Ba}_{8} \mathrm{Ge}_{43}$ is also shown for comparison. The solid arrows indicate superlattice reflections, while open and double arrows indicate reflections from $\mathrm{Ge}$ and type-III clathrate phases, respectively. (b) X-ray powder diffraction pattern in the $2 \theta$ range from $3.5^{\circ}$ to $50^{\circ}$ for the specimen with $X=16$.

$\mathrm{Ba}(\mathrm{Ga}, \mathrm{Ge})_{4}$, and $\mathrm{Ga}$ phases is identified for the specimen with $X=18$, the chemical composition of the type-I clathrate phase corresponds to the solid solubility of $\mathrm{Ga}$ in the $\mathrm{Ba}-\mathrm{Ge}$ normal type-I clathrate phase, which is estimated to be 16.47 per unit formula. The chemical composition of the type-I clathrate phase in the furnace-cooled specimens with $X=4.5$ should correspond to the lower limit for the solid solubility of $\mathrm{Ga}$ in the $\mathrm{Ba}-\mathrm{Ge}$ normal type-I clathrate phase, which is estimated to be 4.72 per unit formula. It is noteworthy in Table I that the total content of Ga and Ge is less than 46 and increases with the increase in the Ga content. This together with the fact that the volume fraction of the $\mathrm{Ge}$ phase decreases with the increase in the Ga content (Figs. 1 and 2) imply that the type-I clathrate compound includes 
some vacancies in the $\mathrm{Ge} / \mathrm{Ga}$ sites and that the density of $\mathrm{Ge}$ vacancies decreases with the increase in the Ga content.

\section{B. Crystal structure analyses}

Crystal structures of phases that exist in all specimens with $X=3-16$ were successfully refined with the Rietveld method, as is evident from the small difference between the observed and calculated intensities shown at the bottom of Fig. 2(b) for the specimen with $X=16$ and from the small values of the reliability factors of the fit $\left(R_{\mathrm{wp}}\right)$, tabulated together with the refined structure parameters in Tables II and III. In the analyses, we assumed that Ga and Ge atoms are randomly distributed in the cage framework with the occupancy ratio given from the results of EDS analyses (Table I) for all type-I clathrate compounds, as in the cases for $\mathrm{Sr}_{8} \mathrm{Ga}_{16} \mathrm{Ge}_{30}$ and $\mathrm{Eu}_{8} \mathrm{Ga}_{16} \mathrm{Ge}_{30} .{ }^{19,20}$ It is noted in the tables that a fraction $(\sim 3 \%)$ of $\mathrm{Ba}$ atoms are deficient in both $\mathrm{Ba}(1)$ and $\mathrm{Ba}(2)$ sites in all type-I clathrate compounds and that the values of ADPs at the $\mathrm{Ba}(2)$ sites ( $6 d$ sites) are considerably large. Mass density measurements for the specimen with $X=16$ indicate that there is $0.8 \%$ deficiency when compared to the theoretical density calculated with the nominal composition and the obtained lattice parameter. If this deficiency is due solely to $\mathrm{Ba}$ vacancies, the fraction of $\mathrm{Ba}$ vacancies is estimated to be $3 \%$, which is consistent with the value of deficiency as obtained by the Rietveld refinement.

Although the type-I clathrate phase in the oil-quenched specimen with $X=3$ possesses the superstructure identical to that of $\mathrm{Ba}_{8} \mathrm{Ge}_{43}$ with the same density of $\mathrm{Ge}$ vacancies, the distribution of $\mathrm{Ge}$ vacancies is somewhat different from that in $\mathrm{Ba}_{8} \mathrm{Ge}_{43}$. Ge vacancies are allocated exclusively in $24 c$ and $24 d$ sites in the superlattice corresponding to the $6 c$ sites of the normal type-I structure (space group $P m \overline{3} m$ ) for specimens with both $X=0$ and 3 . The $24 c$ and $24 d$ sites are exclusively occupied, respectively, by vacancies and Ge atoms in $\mathrm{Ba}_{8} \mathrm{Ge}_{43},{ }^{8,9}$ whereas in the type-I compound in the specimen with $X=3,24$ Ge vacancies (per superlattice unit cell) are distributed in both $24 c$ and $24 d$ sites so as to give the occupancies for $\mathrm{Ge} / \mathrm{Ga}$ atoms of 0.150 and 0.850 in the $24 c$ and $24 d$ sites, respectively (Table II).

The occupancies of $\mathrm{Ge} / \mathrm{Ga}(1)$ atoms ( $6 c$ sites) of the normal type-I clathrate compounds in specimens with $X$ $=4.5,6,12$, and 16 are $0.657,0.684,0.940$, and 0.995 , respectively (Table III), i.e., they include $2.06,1.90,0.36$, and $0.03 \mathrm{Ge}$ vacancies per unit formula, respectively. These $\mathrm{Ge}$ vacancies randomly occupy the $6 c$ sites to form the normal type-I clathrate structure, in contrast to the cases of the type-I compounds observed in specimens with both $X=0$ and 3 . The chemical compositions and the number of Ge vacancies per unit formula in these type-I clathrate compounds are tabulated in Table IV. The density of Ge vacancies in the type-I clathrate compounds decreases with the increase in the Ga content. This is consistent with the fact that the volume fraction of the Ge phase in specimens with $X=3-16$ decreases with the increase in the Ga content (Figs. 1 and 2).

The lattice constant for the type-I clathrate compounds obtained by the Rietveld analyses is plotted in Fig. 4 as a function of Ga content. The lattice constants of the super-
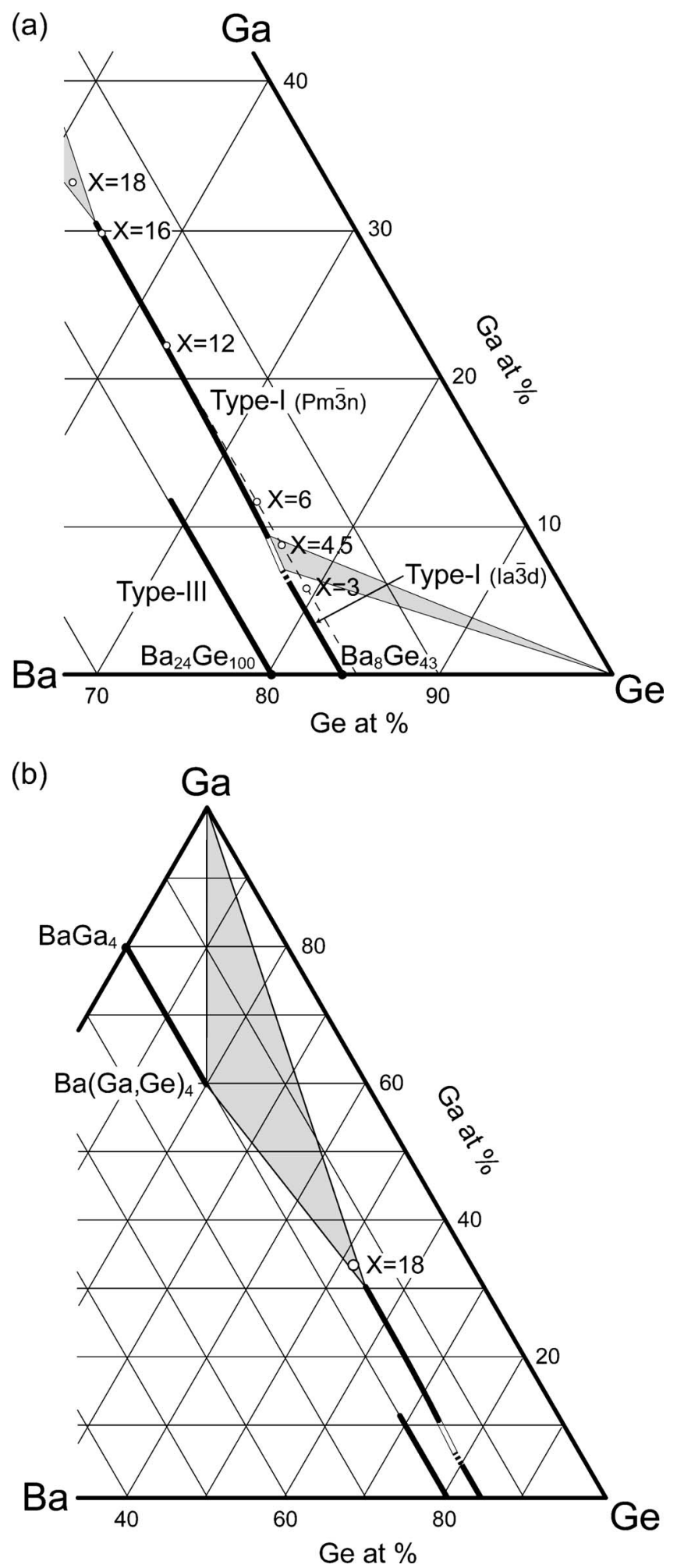

FIG. 3. Portions of the ternary phase diagram in the $\mathrm{Ba}-\mathrm{Ga}-\mathrm{Ge}$ system at $790{ }^{\circ} \mathrm{C}$. The broken line corresponding to compositions of type-I clathrate compounds formed without any Ge vacancies is also drawn. The open circles correspond to the nominal compositions of the specimens used.

structure $(I a \overline{3} d)$ are divided by 2 to compare with that of the normal structure. The lattice constant increases with the increase in the Ga content due to the larger atomic radius of $\mathrm{Ga}$ than that of $\mathrm{Ge}^{21}$ Of interest to note in Fig. 4 is that the lattice constant of the normal type-I clathrate compounds increases with the Ga content more rapidly than that of the 
TABLE II. Results of Rietveld refinement for the type-I clathrate phase in the specimen with $X=3$. The space group is $I a \overline{3} d$ and the lattice parameter is $2.12891(2) \mathrm{nm}$. The residual parameters $R_{w p}$ and $R_{p}$ are 0.0256 and 0.0185 , respectively.

\begin{tabular}{lllllll}
\hline \hline Atom & Site & Occupanay & \multicolumn{1}{c}{$x$} & \multicolumn{1}{c}{$y$} & \multicolumn{2}{c}{ ADP $\left(\mathrm{pm}^{2}\right)$} \\
\hline $\mathrm{Ba}(1)$ & $16 a$ & $0.978(4)$ & 0 & 0 & 0 & $90(5)$ \\
$\mathrm{Ba}(2)$ & $48 g$ & $0.981(3)$ & $1 / 8$ & $0.2478(1)$ & $1 / 4-\mathrm{y}$ & $286(4)$ \\
$\mathrm{Ge} / \mathrm{Ga}(1)$ & $24 c$ & $0.150(1)$ & $1 / 8$ & 0 & $1 / 4$ & $121(4)$ \\
$\mathrm{Ge} / \mathrm{Ga}(2)$ & $24 d$ & $0.850(1)$ & $3 / 8$ & 0 & $1 / 4$ & 121 \\
$\mathrm{Ge} / \mathrm{Ga}(3)$ & $32 e$ & 1.000 & $0.0915(1)$ & $x$ & $x$ & 121 \\
$\mathrm{Ge} / \mathrm{Ga}(4)$ & $96 h$ & 1.000 & $0.4064(1)$ & $0.0909(1)$ & $0.0907(1)$ & 121 \\
$\mathrm{Ge} / \mathrm{Ga}(5)$ & $96 h$ & 1.000 & $0.0005(1)$ & $0.1649(1)$ & $0.0641(1)$ & 121 \\
$\mathrm{Ge} / \mathrm{Ga}(6)$ & $96 h$ & 1.000 & $-0.0002(2)$ & $0.1538(1)$ & $0.4431(1)$ & 121 \\
\hline \hline
\end{tabular}

superlattice type-I clathrate compounds. This may result from the fact that the density of Ge vacancies in the superlattice type-I clathrate compounds is constant (24 per unit cell), while that in the normal type-I clathrate compounds decreases with the increase in the Ga content. Ge vacancies may relax the framework, reducing the lattice constant.

\section{Ternary phase diagram}

Based on the results obtained, a portion of the ternary phase diagram in the $\mathrm{Ba}-\mathrm{Ga}-\mathrm{Ge}$ system at $790^{\circ} \mathrm{C}$ is depicted in Fig. 3. The extension of the solid solubility region for the corresponding type-III clathrate compounds drawn in Fig. 4 is from our preliminary work. ${ }^{22}$ The extension of the solid solubility region for the corresponding type-I clathrate compounds is illustrated in Fig. 3 as the solid line that connects the actual compositions of the type-I clathrate compounds deduced from the crystal structure refinements (Sec. III B). For comparison, the broken line corresponding to compositions of type-I clathrate compounds formed without any $\mathrm{Ge}$ vacancies is also drawn. Evidently, the density of Ge vacancies in the type-I clathrate compounds decreases with the increase in the Ga content. Two different triangles corresponding to the three-phase regions $(\mathrm{Ge}+$ normal type-I clathrate+superlattice type-I clathrate phases and $\mathrm{Ga}$ + normal type-I clathrate $+\mathrm{BaGa}_{4}$ phases) are located near the $\mathrm{Ge}$ and $\mathrm{Ga}$ corners, respectively.

\section{Thermoelectric properties}

Figure 5(a) shows the temperature dependence of electrical resistivity for specimens with $X=0-16 . \mathrm{Ba}_{8} \mathrm{Ge}_{43}$ exhibits a temperature dependence of semiconductor below $400{ }^{\circ} \mathrm{C}$. The anomaly in values of electrical resistivity above $400{ }^{\circ} \mathrm{C}$ for $\mathrm{Ba}_{8} \mathrm{Ge}_{43}$ as well as that above $500{ }^{\circ} \mathrm{C}$ for the specimen with $X=3$ is due to the phase decomposition of the superlattice type-I clathrate phase into type-III clathrate and Ge phases, which is actually confirmed by SEM observations after the measurement. The temperature where the anomaly occurs increases from $400{ }^{\circ} \mathrm{C}$ for $\mathrm{Ba}_{8} \mathrm{Ge}_{43}$ to $500{ }^{\circ} \mathrm{C}$ for the specimen with $X=3$. This is considered to be due to the increased thermal stability of the superlattice type-I clathrate compounds upon alloying with Ga. Values of electrical resistivity at $50{ }^{\circ} \mathrm{C}$ are plotted in the inset of Fig. 5(a) as a function of Ga content. The values of electrical resistivity for the normal type-I clathrate compounds are smaller than those for the superlattice type-I clathrate compounds. The values of electrical resistivity increase with the increase in the Ga con-

TABLE III. Results of Rietveld refinement for the type-I clathrate phase in the specimens with $X=4.5-16$. The space group is $P m \overline{3} n$ and atom positions are $\mathrm{Ba}(1) 2 a 0,0,0 ; \mathrm{Ba}(2) 6 d 1 / 4,1 / 2,0 ; \mathrm{Ge} / \mathrm{Ga}(1) 6 c$ 1/4,0,1/2; $\mathrm{Ge} / \mathrm{Ga}(2) 16 i x, x, x$; and $\mathrm{Ge} / \mathrm{Ga}(3) 24 k 0, y, z$.

\begin{tabular}{lcccc}
\hline \hline Nominal composition & $\mathrm{Ba}_{8} \mathrm{Ga}_{4.5} \mathrm{Ge}_{41.5}$ & $\mathrm{Ba}_{8} \mathrm{Ga}_{6} \mathrm{Ge}_{40}$ & $\mathrm{Ba}_{8} \mathrm{Ga}_{12} \mathrm{Ge}_{34}$ & $\mathrm{Ba}_{8} \mathrm{Ga}_{16} \mathrm{Ge}_{30}$ \\
\hline Lattice parameter $(\mathrm{nm})$ & $1.06666(1)$ & 1.06881 & $1.07406(1)$ & $1.07661(1)$ \\
$R_{\text {wp }}$ & 0.0232 & 0.0266 & 0.0354 & 0.0298 \\
$R_{p}$ & 0.0160 & 0.0191 & 0.0227 & 0.0211 \\
$g[\mathrm{Ba}(1)]$ & $0.944(3)$ & $0.970(4)$ & $0.942(5)$ & $0.979(2)$ \\
$\mathrm{ADP}[\mathrm{Ba}(1)]\left(\mathrm{pm}^{2}\right)$ & $98(5)$ & $114(4)$ & $118(6)$ & $121(4)$ \\
$g[\mathrm{Ba}(2)]$ & $0.968(4)$ & $0.977(3)$ & $0.980(5)$ & $0.971(2)$ \\
$\mathrm{ADP}[\mathrm{Ba}(2)]\left(\mathrm{pm}^{2}\right)$ & $323(4)$ & $346(4)$ & $358(6)$ & $397(4)$ \\
$g[\mathrm{Ge} / \mathrm{Ga}(1)]$ & $0.657(1)$ & $0.684(1)$ & $0.940(2)$ & $0.955(1)$ \\
$\mathrm{ADP}[\mathrm{Ge} / \mathrm{Ga}(1)]\left(\mathrm{pm}^{2}\right)$ & $138(10)$ & $156(7)$ & $148(8)$ & $112(3)$ \\
$g[\mathrm{Ge} / \mathrm{Ga}(2)]$ & 1.000 & 1.000 & 1.000 & 1.000 \\
$\mathrm{ADP}[\mathrm{Ge} / \mathrm{Ga}(2)]\left(\mathrm{pm}^{2}\right)$ & $137(2)$ & $128(2)$ & $127(3)$ & $102(2)$ \\
$x[\mathrm{Ge} / \mathrm{Ga}(2)]$ & $0.1833(1)$ & 0.1836 & $0.1844(1)$ & 0.1845 \\
$g[\mathrm{Ge} / \mathrm{Ga}(3)]$ & 1.000 & 1.000 & 1.000 & 1.000 \\
$\mathrm{ADP}[\mathrm{Ge} / \mathrm{Ga}(3)]\left(\mathrm{pm}^{2}\right)$ & $203(2)$ & $189(2)$ & $130(3)$ & $106(2)$ \\
$y[\mathrm{Ge} / \mathrm{Ga}(3)]$ & $0.3160(1)$ & $0.3146(1)$ & $0.3098(1)$ & $0.3084(1)$ \\
$z[\mathrm{Ge} / \mathrm{Ga}(3)]$ & $0.1201(1)$ & $0.1191(1)$ & $0.1185(1)$ & $0.1182(1)$ \\
\hline \hline
\end{tabular}


TABLE IV. Chemical compositions, number of Ge vacancies, and number of excess electrons per unit formula in the type-I clathrate compounds. The chemical compositions and number of Ge vacancies per unit formula were obtained from EDS and Rietveld analyses, while the number of excess electrons per unit formula was calculated based on the charge compensation concept.

\begin{tabular}{lccc}
\hline \hline $\begin{array}{l}\text { Nominal } \\
\text { composition }\end{array}$ & $\begin{array}{c}\text { Composition } \\
\text { (Rietveld analyses) }\end{array}$ & $\begin{array}{c}\text { Number of } \\
\text { Ge vacancies }\end{array}$ & $\begin{array}{c}\text { Number of } \\
\text { excess electrons }\end{array}$ \\
\hline $\mathrm{Ba}_{8} \mathrm{Ga}_{3} \mathrm{Ge}_{43}$ & $\mathrm{Ba}_{7.84} \mathrm{Ga}_{3.44} \mathrm{Ge}_{39.56}$ & 3.00 & +0.24 \\
$\mathrm{Ba}_{8} \mathrm{Ga}_{4.5} \mathrm{Ge}_{41.5}$ & $\mathrm{Ba}_{7.69} \mathrm{Ga}_{4.86} \mathrm{Ge}_{39.08}$ & 2.06 & +2.28 \\
$\mathrm{Ba}_{8} \mathrm{Ga}_{6} \mathrm{Ge}_{40}$ & $\mathrm{Ba}_{7.80} \mathrm{Ga}_{6.71} \mathrm{Ge}_{37.39}$ & 1.90 & +1.29 \\
$\mathrm{Ba}_{8} \mathrm{Ga}_{12} \mathrm{Ge}_{34}$ & $\mathrm{Ba}_{7.76} \mathrm{Ga}_{13.80} \mathrm{Ge}_{31.84}$ & 0.36 & +0.28 \\
$\mathrm{Ba}_{8} \mathrm{Ga}_{16} \mathrm{Ge}_{30}$ & $\mathrm{Ba}_{7.81} \mathrm{Ga}_{16.82} \mathrm{Ge}_{29.15}$ & 0.03 & -1.32 \\
\hline \hline
\end{tabular}

tent for the normal type-I clathrate compounds. In contrast, the value of electrical resistivity of the superlattice type-I clathrate compounds decreases significantly (almost by two orders of magnitude) with the $\mathrm{Ga}$ content from 8.73 $\times 10^{-4} \Omega \mathrm{m}$ for $X=0$ to $1.87 \times 10^{-5} \Omega \mathrm{m}$ for $X=3$. The temperature dependence of electrical resistivity for all the ternary specimens is of a degenerate semiconductor, while that for the binary specimen is of a semiconductor.

The values of Seebeck coefficient for all specimens are negative in sign ( $n$-type conduction) as shown in Fig. 5(b). The absolute values of Seebeck coefficient increase monotonically with the increase in temperature except for $\mathrm{Ba}_{8} \mathrm{Ge}_{43}$, in which the anomaly arising from the decomposition reaction of the superlattice type-I clathrate phase into $\mathrm{Ge}$ and type-III clathrate phases occurs above $400{ }^{\circ} \mathrm{C}$. The absolute values of Seebeck coefficient for the normal type-I clathrate compounds increase with the increase in the $\mathrm{Ga}$ content.

Figure 5(c) shows the temperature dependence of thermal conductivity for specimens with $X=0-16$. The anomaly in thermal conductivity above $500{ }^{\circ} \mathrm{C}$ for $\mathrm{Ba}_{8} \mathrm{Ge}_{43}$ is also due to the phase decomposition. The value of thermal conductivity for the normal type-I clathrate compounds decreases with the increase in the Ga content. Thermal conductivity for the specimen with $X=16$ is almost tempera-

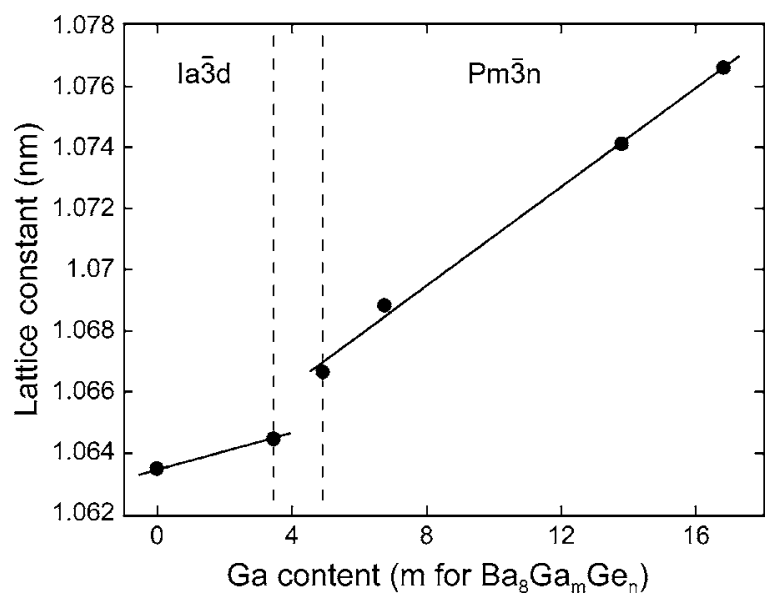

FIG. 4. Lattice constant of the type-I clathrate compounds plotted as a function of Ga content. The Ga contents deduced from EDS analyses (Table I) were used in the plot. ture independent and the value at room temperature is $2.1 \mathrm{~W} / \mathrm{mK}$.

Values of thermoelectric ZT are calculated with the obtained values of electrical resistivity, Seebeck coefficient, and thermal conductivity, and are plotted in Fig. 6 as a function of temperature. The ZT values of superlattice type-I clathrate compounds $(X \leqslant 3)$ are generally smaller than those of normal type-I clathrate compounds $(X \geqslant 4.5)$. The ZT values of normal type-I clathrate compounds increase with the increase in the Ga content and temperature. The highest ZT value of 0.49 is thus obtained at $670{ }^{\circ} \mathrm{C}$ for the specimen with $X=16$.

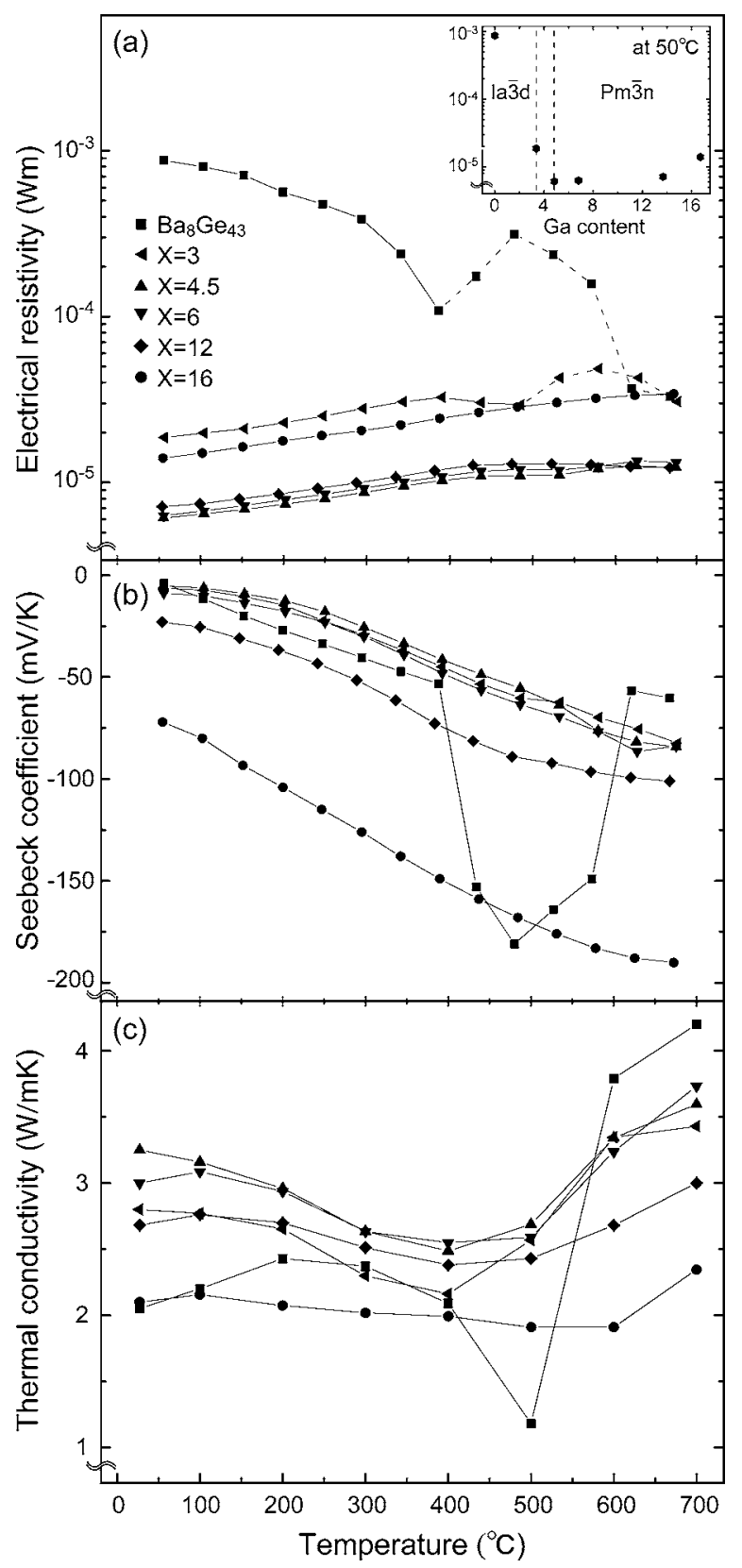

FIG. 5. (a) Electrical resistivity, (b) Seebeck coefficient, and (c) thermal conductivity for the specimens with $X=0-16$ plotted as functions of temperature. The inset in (a) shows the values of electrical resistivity at $50{ }^{\circ} \mathrm{C}$ plotted as a function of $\mathrm{Ga}$ content. 


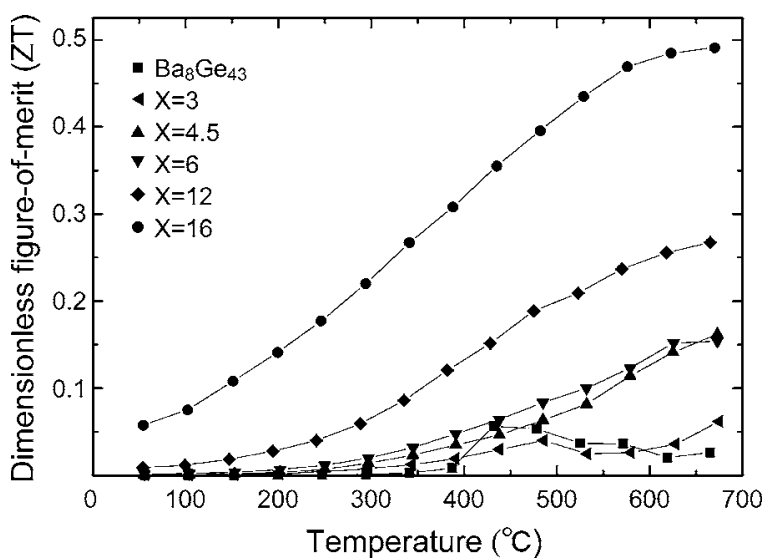

FIG. 6. Dimensionless figure of merit (ZT) for the specimens with $X$ $=0-16$ plotted as a function of temperature.

\section{DISCUSSION}

\section{A. Charge compensation concept}

The concept of charge compensation is sometimes used to describe the transport properties of type-I clathrate compounds. ${ }^{7,10}$ In this concept, guest atoms are considered to donate electrons that are accepted by host (cage) atoms so that the compound can be considered to consist of positively charged guest atoms and negatively charged host cages. Some (or all) of the electrons donated by guest atoms can be compensated by lone pairs formed in the cage structure through alloying ternary elements of group III. Dangling bonds formed around vacancies are expected to do the same. Electrons that are not compensated may act as excess electrons, which may play an important role in the transport properties. According to this concept, $\mathrm{Ba}_{8} \mathrm{Ge}_{43}$ is expected to exhibit a metallic conduction behavior, since only 12 of the 16 electrons donated by eight $\mathrm{Ba}$ atoms $(2 \times 8)$ are compensated by dangling bonds produced by three Ge vacancies $(4 \times 3)$, leaving four excess electrons per unit formula. However, $\mathrm{Ba}_{8} \mathrm{Ge}_{43}$ is a semiconductor with a negative temperature dependence of electrical resistivity below $400{ }^{\circ} \mathrm{C}$ [Fig. 5(a)]. The semiconducting behavior of $\mathrm{Ba}_{8} \mathrm{Ge}_{43}$ has been ascribed to the formation of the superlattice structure with the ordered arrangement of Ge vacancies, which produces a Fermi surface located in the energy band gap. ${ }^{8,23}$

Upon alloying with $\mathrm{Ga}$, charge compensation occurs in the existence of both vacancies and Ga (impurity) atoms. Since Ga belongs to group III, the substitution for Ge with a $\mathrm{Ga}$ atom per unit formula reduces one excess electron. For example, $\mathrm{Ba}_{8} \mathrm{Ga}_{16} \mathrm{Ge}_{30}$ possesses no excess electron because 16 electrons donated by eight $\mathrm{Ba}$ atoms are all compensated by 16 lone pairs produced by $16 \mathrm{Ga}$ atoms and thus charge compensation is fully achieved in this compound. The numbers of excess electrons calculated in this way with the chemical compositions deduced by the Rietveld analyses are tabulated in Table IV. The number of excess electrons that act as charge carriers in the normal type-I clathrate compounds decreases with the increase in the Ga content, giving rise to the increase in the values of electrical resistivity with the Ga content [Fig. 5(a)]. Since the carrier mobility generally increases with the decrease in the carrier concentration,
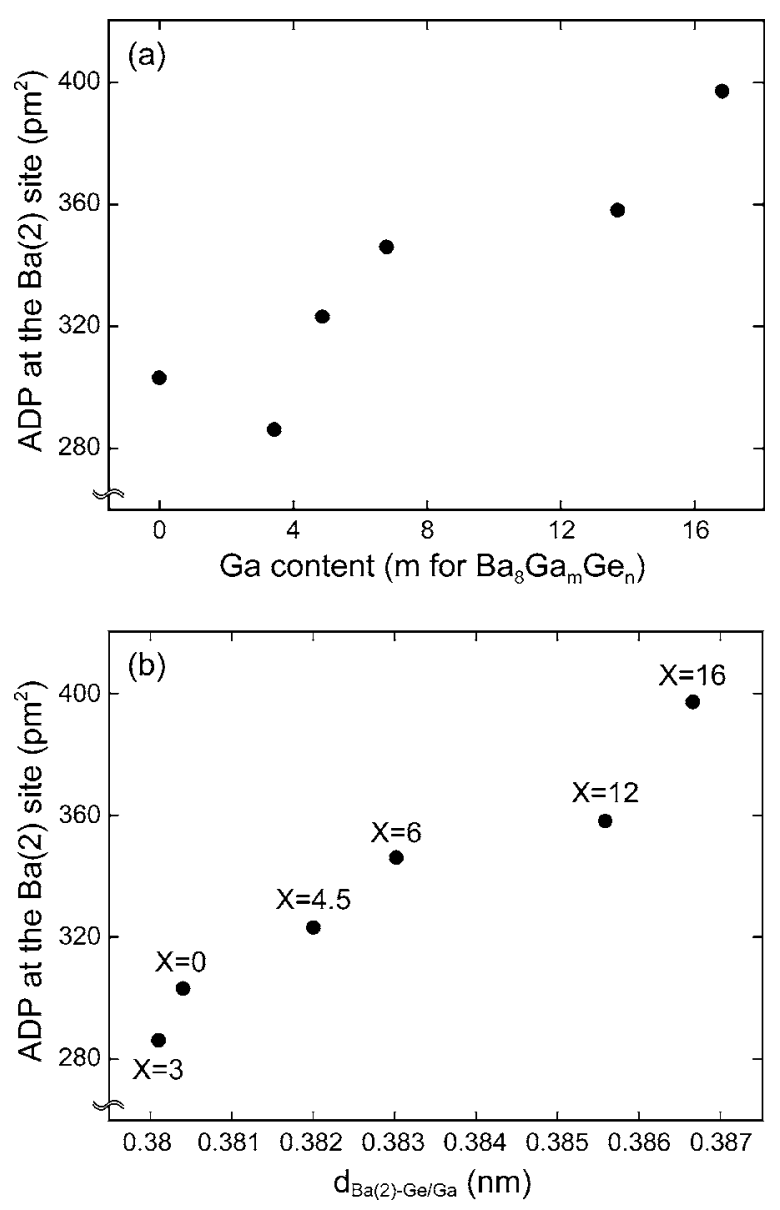

FIG. 7. $\mathrm{ADP}$ at the $\mathrm{Ba}(2)$ site plotted as functions of (a) Ga content and (b) the average bond length between the $\mathrm{Ba}(2)$ atom and encapsulating $\mathrm{Ge} / \mathrm{Ga}$ atoms.

the absolute values of Seebeck coefficient for the present normal type-I clathrate compounds are expected to increase with the Ga content, as experimentally observed [Fig. 5(b)].

Although Anno et al. ${ }^{13}$ report that the solubility limit of $\mathrm{Ga}$ in the type-I clathrate phase in the $\mathrm{Ba}-\mathrm{Ga}-\mathrm{Ge}$ system is extended to about 18 per unit formula and that Seebeck coefficient of specimens with the Ga content more than 16 is positive in sign, however, the present study has revealed that the specimen with $X=18$ exhibits a three-phase microstructure consisting of type-I clathrate, $\mathrm{Ba}(\mathrm{Ga}, \mathrm{Ge})_{4}$, and $\mathrm{Ga}$ phases and that the solubility limit of $\mathrm{Ga}$ in the type-I clathrate phase is only a little larger than 16 per unit formula. Indeed, our measurement indicates that the Seebeck coefficient of specimens with $X=18$ is negative in sign (from -60 to $-40 \mu \mathrm{V} / \mathrm{K})$. Of interest to note is that the Seebeck coefficient of specimens with $X=20$ is positive in sign $(10-20 \mu \mathrm{V} / \mathrm{K})$ in our measurement. In view of the increased volume fraction of $\mathrm{Ba}(\mathrm{Ga}, \mathrm{Ge})_{4}$ and $\mathrm{Ga}$ phases [especially, $\mathrm{Ba}(\mathrm{Ga}, \mathrm{Ge})_{4}$ phase] in the specimen with $X=20$, we believe that the positive sign of the Seebeck coefficient in the specimen with $X=20$ originates from a phase other than the type-I clathrate phase. When referred to the charge compensation concept, it is very difficult to expect the positive sign of the Seebeck coefficient for type-I clathrate compounds in the $\mathrm{Ba}-\mathrm{Ga}-\mathrm{Ge}$ system, since the clathrate compound is considered to stabilize its structure by attractive force between 
TABLE V. Atomic bond lengths and numbers of the corresponding atomic bonds for the type-I clathrate phase in the specimen with $X=3$. The symbols "prime" and "double prime" were used to differentiate crystallographycally equivalent $\mathrm{Ge} / \mathrm{Ga}$ sites with different bond lengths from each other.

\begin{tabular}{lcc}
\hline \hline & Length (nm) & $n_{i}$ \\
\hline $\mathrm{Ba}(2)-\mathrm{Ge} / \mathrm{Ga}(1)$ & 0.3731 & 96 \\
$\mathrm{Ba}(2)-\mathrm{Ge} / \mathrm{Ga}(2)$ & 0.3731 & 96 \\
$\mathrm{Ba}(2)-\mathrm{Ge} / \mathrm{Ga}(3)$ & 0.3898 & 96 \\
$\mathrm{Ba}(2)-\mathrm{Ge} / \mathrm{Ga}(4)$ & 0.3934 & 96 \\
$\mathrm{Ba}(2)-\mathrm{Ge} / \mathrm{Ga}\left(4^{\prime}\right)$ & 0.3936 & 96 \\
$\mathrm{Ba}(2)-\mathrm{Ge} / \mathrm{Ga}\left(4^{\prime \prime}\right)$ & 0.4060 & 96 \\
$\mathrm{Ba}(2)-\mathrm{Ge} / \mathrm{Ga}(5)$ & 0.3444 & 96 \\
$\mathrm{Ba}(2)-\mathrm{Ge} / \mathrm{Ga}\left(5^{\prime}\right)$ & 0.3509 & 96 \\
$\mathrm{Ba}(2)-\mathrm{Ge} / \mathrm{Ga}\left(5^{\prime \prime}\right)$ & 0.3999 & 96 \\
$\mathrm{Ba}(2)-\mathrm{Ge} / \mathrm{Ga}(6)$ & 0.3554 & 96 \\
$\mathrm{Ba}(2)-\mathrm{Ge} / \mathrm{Ga}\left(6^{\prime}\right)$ & 0.3614 & 96 \\
$\mathrm{Ba}(2)-\mathrm{Ge} / \mathrm{Ga}\left(6^{\prime \prime}\right)$ & 0.4200 & 96 \\
$\mathrm{Ba}(2)-\mathrm{Ge} / \mathrm{Ga}$ average & 0.3801 & $\cdots$ \\
\hline \hline
\end{tabular}

positively charged guest atoms and negatively charged host cages. ${ }^{24}$ As described previously, charge compensation is considered to be fully achieved in $\mathrm{Ba}_{8} \mathrm{Ga}_{16} \mathrm{Ge}_{30}$ and the compound is free from excess electrons. If $\mathrm{Ba}_{8} \mathrm{Ga}_{16} \mathrm{Ge}_{30}$ is further alloyed with $\mathrm{Ga}$, the cage framework would be electron deficient and positively charged. Then, repulsive force would arise between the positively charged guest atoms and the cage framework, making the structure unstable. This is consistent with the fact that the solubility limit of $\mathrm{Ga}$ in the type-I clathrate phase is about 16 per unit formula.

\section{B. Lattice thermal conductivity}

The low thermal conductivity of clathrate compounds has been reported to be associated with the rattling motion of guest atoms, which can be monitored with an anomalously large ADP by x-ray diffraction. ${ }^{5}$ For the type-I clathrate compounds in the $\mathrm{Ba}-\mathrm{Ga}-\mathrm{Ge}$ system, the value of $\mathrm{ADP}$ at the $\mathrm{Ba}(2)$ site ( $6 d$ site) in the tetrakaidecahedral cage is considerably large (Tables II and III) and increases with the increase in the Ga content except for the specimen with $X=3$, as shown in Fig. 7(a). Since the lattice parameter increases with the increase in the Ga content (Fig. 4), the value of ADP at the $\mathrm{Ba}(2)$ site may be related to the size of the tetrakaid- ecahedral cage that can be expressed with the average bond length $\bar{d}$ between a $\mathrm{Ba}(2)$ atom and encapsulating $\mathrm{Ge} / \mathrm{Ga}$ atoms as follows:

$$
\bar{d}=\frac{\sum_{i}\left(n_{i} \times d_{i}\right)}{\sum_{i} n_{i}},
$$

where $d_{i}$ and $n_{i}$ stand for the $\mathrm{Ba}(2)-\mathrm{Ge} / \mathrm{Ga}$ bond length and the number of the bond, respectively. The values of $d_{i}$ and $n_{i}$ for each of the type-I clathrate compounds calculated from the structure refinement results are tabulated in Tables $\mathrm{V}$ and VI. The value of ADP at the $\mathrm{Ba}(2)$ site indeed increases with the increase in the average $\mathrm{Ba}(2)-\mathrm{Ge} / \mathrm{Ga}$ bond length (i.e., the size of the tetrakaidecahedral cage), as shown in Fig. 7(b). Sales et al. ${ }^{25}$ have reported that in $M_{8} \mathrm{Ga}_{16} \mathrm{Ge}_{30}(M$ $=\mathrm{Ba}, \mathrm{Sr}, \mathrm{Eu}$ ), while the size of the tetrakaidecahedral cage does not depend on guest $M$ atom, the value of ADP at the $M(2)$ site increases with the decrease in the radius of the guest $M$ atom. This together with our result shown in Fig. 7(b) indicate that the value of ADP at the $M(2)$ site tends to increase with the increase in the distance between the cage and the encapsulated guest atom and that a clathrate compound with a large cage size and a small guest atom may exhibit a large value of ADP.

We estimate the lattice component of thermal conductivity $\lambda_{\text {lattice }}$, assuming that the Wiedemann-Franz approximation ${ }^{26}$ is valid in evaluating the electronic contribution of thermal conductivity $\lambda_{\text {electron }}$ as follows:

$$
\lambda_{\text {lattice }}=\lambda_{\text {total }}-\lambda_{\text {electron }}=\lambda_{\text {total }}-L T / \rho,
$$

where $\lambda_{\text {total }}$ and $L$ stand for the total thermal conductivity and the Lorenz number $\left(2.44 \times 10^{-8} \Omega \mathrm{W} / \mathrm{K}^{2}\right)$, respectively. The calculated values of lattice thermal conductivity at room temperature are plotted in Fig. 8(a) as a function of Ga content. The value of lattice thermal conductivity tends to decrease with the increase in the Ga content, except for the specimen with $X=3$. The calculated values of lattice thermal conductivity at room temperature are also plotted in Fig. 8(b) as a function of value of ADP at the $\mathrm{Ba}(2)$ site. The values of lattice thermal conductivity correlates inversely with those of $\mathrm{ADP}$ at the $\mathrm{Ba}(2)$ sites. The relatively high value of lattice thermal conductivity of the specimen with $X=3$ [Fig. 8(a)] is obviously due to the relatively low value of ADP at the $\mathrm{Ba}(2)$ site [Fig. 7(a)]. Impurity (Ga) scattering may play a role in

TABLE VI. Atomic bond lengths and numbers of the corresponding atomic bonds for the normal type-I clathrate phase in the specimen with $X=4.5-16$. The symbol "prime" was used to differentiate crystallographycally equivalent $\mathrm{Ge} / \mathrm{Ga}$ sites with different bond lengths from each other.

\begin{tabular}{lcccc}
\hline \hline & $\mathrm{Ba}_{8} \mathrm{Ga}_{4.5} \mathrm{Ge}_{41.5}$ & $\mathrm{Ba}_{8} \mathrm{Ga}_{6} \mathrm{Ge}_{40}$ & $\mathrm{Ba}_{8} \mathrm{Ga}_{12} \mathrm{Ge}_{34}$ & $\mathrm{Ba}_{8} \mathrm{Ga}_{16} \mathrm{Ge}_{30}$ \\
\hline$d_{\mathrm{Ba}(2)-\mathrm{Ge} / \mathrm{Ga}(1)}(\mathrm{nm})$ & 0.3771 & 0.3779 & 0.3798 & 0.3806 \\
$n_{\mathrm{Ba}(2)-\mathrm{Ge} / \mathrm{Ga}(1)}$ & 24 & 24 & 24 & 24 \\
$d_{\mathrm{Ba}(2)-\mathrm{Ge} / \mathrm{Ga}(2)}(\mathrm{nm})$ & 0.3967 & 0.3974 & 0.3989 & 0.3998 \\
$n_{\mathrm{Ba}(2)-\mathrm{Ge} / \mathrm{Ga}(2)}$ & 48 & 48 & 48 & 48 \\
$d_{\mathrm{Ba}(2)-\mathrm{Ge} / \mathrm{Ga}(3)}(\mathrm{nm})$ & 0.3550 & 0.3562 & 0.3606 & 0.3622 \\
$n_{\mathrm{Ba}(2)-\mathrm{Ge} / \mathrm{Ga}(3)}$ & 48 & 48 & 48 & 48 \\
$d_{\mathrm{Ba}(2)-\mathrm{Ge} / \mathrm{Ga}\left(3^{\prime}\right)}(\mathrm{nm})$ & 0.4113 & 0.4129 & 0.4148 & 0.4158 \\
$n_{\mathrm{Ba}(2)-\mathrm{Ge} / \mathrm{Ga}\left(3^{\prime}\right)}$ & 24 & 24 & 24 & 24 \\
$d_{\mathrm{Ba}(2)-\mathrm{Ge} / \mathrm{Ga}}$ average $(\mathrm{nm})$ & 0.3820 & 0.3830 & 0.3856 & 0.3867 \\
\hline \hline
\end{tabular}



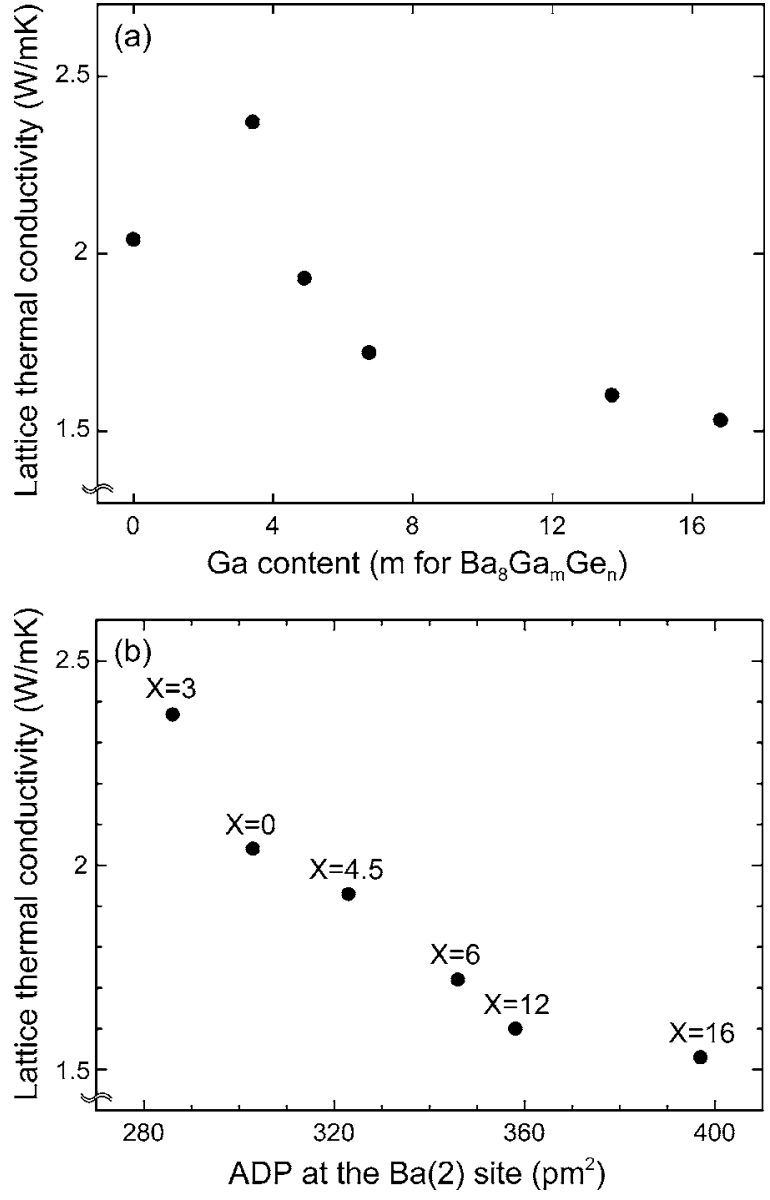

FIG. 8. Lattice thermal conductivity at room temperature plotted as functions of (a) Ga content and (b) ADP at the $\mathrm{Ba}(2)$ site.

reducing the value of lattice thermal conductivity as the Ga content increases. However, in view of the fact that the value of lattice thermal conductivity of the ternary specimen with $X=3$ is larger than that of the binary specimen, we believe that the rattling motion of the $\mathrm{Ba}(2)$ atoms rather than impurity scattering is a dominant factor for the reduction of lattice thermal conductivity in the present type-I clathrate compounds. Since the value of ADP at the $\mathrm{Ba}(2)$ site increases with the size of the tetrakaidecahedral cage [Fig. 7(b)], the value of lattice thermal conductivity is expected to decrease with the increase in the size of the tetrakaidecahedral cage. Thus, substitution for Ge atoms with ternary elements that effectively increase the lattice constant is expected to significantly reduce the value of lattice thermal conductivity of the Ba-Ge type-I clathrate compounds

\section{CONCLUSIONS}

The solid solubility of $\mathrm{Ga}$ in the $\mathrm{Ba}-\mathrm{Ge}$ type-I clathrate compounds is determined to be $X=16$ when expressed with the formula of $\mathrm{Ba}_{8} \mathrm{Ga}_{X} \mathrm{Ge}_{46-X}$.

As the Ga content increases, the crystal structure changes from a superlattice structure with an ordered arrangement of Ge vacancies (space group $I a \overline{3} d$ ) to the normal type-I clathrate structure (space group $P m \overline{3} n$ ) with Ge vacan- cies randomly distributed in $6 c$ sites. The density of Ge vacancies in the normal type-I clathrate phase decreases with the increase in the Ga content.

The absolute values of electrical resistivity and Seebeck coefficient for the normal type-I clathrate compounds increase with the increase in the Ga content. The changes in these properties are explained in terms of changes in the number of excess electrons that can be calculated with the concept of charge compensation.

The values of lattice thermal conductivity for the type-I clathrate compounds decrease with the increase in the $\mathrm{Ga}$ content. The changes in thermal conductivity are explained in terms of changes in the extent of the rattling motion of $\mathrm{Ba}$ atoms encapsulated in the cage structure, which increase with the increase in the size of the tetrakaidecahedral cage.

The ZT values of the normal type-I clathrate compounds increase with the increase in the Ga content and temperature. The highest ZT value of 0.49 is obtained at $670{ }^{\circ} \mathrm{C}$ for the specimen with $X=16$.

\section{ACKNOWLEDGMENTS}

This work was supported by Grant-in-Aid for Scientific Research (a) from the Ministry of Education, Science, Sports, and Culture of Japan (Grant No. 17656227) and in part by the 21st Century COE (Center of Excellence) Program on United Approach for New Materials Science from the Ministry of Education, Science, Sports, and Culture of Japan. One of the authors (N.L.O.) greatly appreciates the support from Research Fellowships of the Japan Society for the Promotion of Science for Young Scientists. The synchrotron radiation experiments were performed at the SPring-8 with the approval of the Japan Synchrotron Radiation Research Institute (JASRI) (Proposal No. 2003B0701-ND1c$\mathrm{np).}$

${ }^{1}$ G. S. Nolas, Mater. Res. Soc. Symp. Proc. 545, 435 (1999).

${ }^{2}$ G. A. Slack, in CRC Handbook of Thermoelectrics, edited by D. M. Rowe (CRC, Boca Raton, FL, 1995), p. 407.

${ }^{3}$ G. S. Nolas, J. L. Cohn, G. A. Slack, and S. B. Schujman, Appl. Phys. Lett. 73, 178 (1998).

${ }^{4}$ B. Eisenmann, H. Schäfer, and R. Zagler, J. Less-Common Met. 118, 43 (1986).

${ }^{5}$ G. S. Nolas, T. J. R. Weakley, J. L. Cohn, and R. Sharma, Phys. Rev. B 61, 3845 (2000).

${ }^{6}$ R. F. W. Herrmann, K. Tanigaki, T. Kawaguchi, S. Kuroshima, and O. Zhou, Phys. Rev. B 60, 13245 (1999).

${ }^{7}$ W. C. Cabrera, S. Budnyk, Y. Prots, and Y. Grin, Z. Anorg. Allg. Chem. 630, 2267 (2004).

${ }^{8}$ N. L. Okamoto, M. W. Oh, T. Nishii, K. Tanaka, and H. Inui, J. Appl. Phys. 99, 033513 (2006).

${ }^{9}$ N. L. Okamoto, K. Tanaka, and H. Inui, Acta Mater. 54, 173 (2006).

${ }^{10}$ J.-T. Zhao and J. D. Corbett, Inorg. Chem. 33, 5721 (1994).

${ }^{11}$ H.-G. von Schnering, Nova Acta Leopold. 59, 168 (1985).

${ }^{12}$ G. S. Nolas, B. C. Chakoumakos, B. Mahieu, G. J. Long, and T. J. R. Weakley, Chem. Mater. 12, 1947 (2000).

${ }^{13}$ H. Anno, M. Hokazono, M. Kawamura, J. Nagao, and K. Matsubara, Proceedings of the 21st International Conference on Thermoelectrics (IEEE, Piscataway, NJ, 2002), p. 77.

${ }^{14} \mathrm{~L}$. Bertini et al., Proceedings of the 22nd International Conference on Thermoelectrics (IEEE, Piscataway, NJ, 2003), p. 127.

${ }^{15}$ G. Cordier and P. Woll, J. Less-Common Met. 169, 291 (1991).

${ }^{16}$ A. P. Wilkinson, C. Lind, R. A. Young, S. D. Shastri, P. L. Lee, and G. S. Nolas, Chem. Mater. 14, 1300 (2002). 
${ }^{17}$ F. Izumi and T. Ikeda, Mater. Sci. Forum 321, 198 (2000).

${ }^{18}$ S. Paschen, W. C. Cabrera, A. Bentien, V. H. Tran, M. Baenitz, Y. Grin, and F. Steglich, Phys. Rev. B 64, 214404 (2001).

${ }^{19}$ B. C. Chakoumakos, B. C. Sales, D. G. Mandrus, and G. S. Nolas, J. Alloys Compd. 296, 80 (2000).

${ }^{20}$ B. C. Chakoumakos, B. C. Sales, and D. G. Mandrus, J. Alloys Compd. 322, 127 (2001)

${ }^{21}$ L. Pauling, The Nature of Chemical Bond, 3rd ed. (Cornell University Press, New York, 1960).
${ }^{22}$ J. H. Kim, N. L. Okamoto, K. Kishida, K. Tanaka, and H. Inui, Acta Mater. 54, 2057 (2006).

${ }^{23}$ J. F. Nicholas, Proc. Phys. Soc., London, Sect. A 66, 201 (1953).

${ }^{24}$ C. Gatti, L. Bertini, N. P. Blake, and B. B. Iversen, Chem.-Eur. J. 9, 4556 (2003).

${ }^{25}$ B. C. Sales, B. C. Chakoumakos, R. Jin, J. R. Thompson, and D. Mandrus, Phys. Rev. B 63, 245113 (2001).

${ }^{26}$ N. W. Ashcroft and N. D. Mermin, Solid State Physics (Harcourt, Orlando, FL, 1976), p. 323. 